\title{
The Photoperiod-regulated Bud Formation of Red Pitaya (Hylocereus sp.)
}

\author{
Yi-Lu Jiang, Yuan-Yin Liao, Tzong-Shyan Lin, and Ching-Lung Lee \\ Department of Horticulture and Landscape Architecture, National Taiwan \\ University, No. 1, Sec. 4, Roosevelt Road, Taipei 106, Taiwan, R.O.C.
}

\section{Chung-Ruey Yen}

Department of Plant Industry, National Pingtung University of Science and Technology, Pingtung 912, Taiwan, R.O.C.

\author{
Wen-Ju Yang ${ }^{1}$ \\ Department of Horticulture and Landscape Architecture, National Taiwan \\ University, No. 1, Sec. 4, Roosevelt Road, Taipei 106, Taiwan, R.O.C.
}

Additional index words. day length, equinox, flower thinning, long-day plant, night-breaking

\begin{abstract}
Red pitaya (Hylocereus sp.), which flowers between May and October and sprouts between November and May in Taiwan, has been confirmed to be a long-day plant. The areoles on the old shoots may be induced to flower after the March equinox naturally, and the floral bud formation occurs in two to three waves from May to October. We conducted experiments on photoperiodic regulation of floral bud formation from June to Dec. 2009 and tested the feasibility of off-season production in 2011. Shortening summer daylength to $8 \mathrm{~h}$ inhibited the areoles at the distal end of the shoots to develop into floral buds and promoted sprouting at the proximal ends of the shoots. Night-breaking treatment between the September equinox and the winter solstice led to floral bud formation. The critical daylength seemed to be $\approx 12 \mathrm{~h}$, and night-breaking treatment would be applicable between the September and the next March equinoxes to produce off-season crops. The duration of night-breaking required for flower differentiation was longer in the cooler than in the warmer season. Four weeks of night-breaking treatment was sufficient to promote flowering in late fall (mid-October to midNovember), but 3 months were required to generate similar result in the winter and early spring (January to March) in southern Taiwan.
\end{abstract}

Pitaya is increasing in popularity as a crop partial as a result of its tolerance to arid environments and resistance to pathogens (Mizrahi et al., 1997, 2002; Mizrahi and Nerd, 1999; Nobel and De La Barrera, 2004). Both Hylocereus undatus (Haworth) Britt. \& Rose and red pitaya $(H$. sp.) have been introduced to Taiwan in recent decades. The most commonly grown red pitaya varieties were selected from crosses between $H$. undatus and $H$. spp., and they produce fruit in summer and fall (Hsu, 2004). Breeding for winter-bearing cultivars as well as developing methods to regulate flowering to produce winter crops would benefit the red pitaya industry (Chang, 2003; Jiang, 2005; Jiang et al., 2011; Yen and Chang, 1997).

Factors affecting flowering of pitaya include shoot age, temperature, light, and application of growth regulators. For yellow pitaya (Selenicereus megalanthus), shoots that sprout in spring normally flower in winter, whereas shoots that sprout in winter flower in the next fall (Jiang et al., 2011). Regardless of daylength, extreme temperatures in summer may restrict the flowering of pitaya

Received for publication 3 Apr. 2012. Accepted for publication 12 June 2012.

${ }^{1}$ To whom reprint requests should be addressed; e-mailwendy@ntu.edu.tw.
(Nerd et al., 2002). Light intensity may affect the nutritional status of shoots and thus influence the number of flowers produced, but it does not promote off-season flowering in H. undatus (Khaimov and Mizrahi, 2006; Raveh et al., 1998). Flower thinning and application of growth regulators such as [N-(2chloro-4-pyridinyl)-N-phenylurea] (CPPU) and gibberellic acid $\left(\mathrm{GA}_{3}\right)$ could accelerate flowering or extend the flowering period and therefore result in earlier or later harvest, but they did not reverse the seasonal flowering phenology in H. undatus (Khaimov and Mizrahi, 2006). A number of other chemicals related to floral initiation, including sodium naphthalene acetic acid, ethephon (Ethrel ${ }^{\mathrm{TM}}$ ), ethephon with urea, a commercial mixture of gibberellins $\left(\mathrm{GA}_{4}\right.$ and $\left.\mathrm{GA}_{7}\right)$ with benzyl adenine known as Perlan ${ }^{\mathrm{TM}}$, paclobutrazol, hydrogen cyanamide, 2-ethylene chlorohydrin, $\mathrm{KNO}_{3}$, and $\mathrm{CaC}_{2}$, have been tested but did not promote winter flowering of pitaya (Chang, 2003; Khaimov and Mizrahi, 2006; Yen and Chang, 1997).

Pitaya is generally known as a long-day plant, which flowers in several flushes between May and October in the northern hemisphere according to Luders and McMahon (2006). To verify the long-day plant status of pitaya, other researchers have conducted experiments involving daylength manipulation. Yen and Chang (1997) prolonged the light period to $2200 \mathrm{HR}$ between November and March to encourage $H$. undatus plants to flower inside a plastic house but only had limited success. Khaimov and Mizrahi (2006) obtained a contradictory result from their experiments extending daylength between March and July. To date, the photoperiodism of pitaya has not been clearly demonstrated by conclusive data, and the application of nightbreaking or daylength extension for winter crop production remains unstable in subtropical Taiwan. This study verified that red pitaya is a long-day plant and that nightbreaking treatment can promote its winter crop production.

\section{Material and Methods}

Plant materials. Five-year-old red pitaya clone-cutting plants in a commercial plantation in Yilan, northeastern Taiwan (lat. $24^{\circ} 45^{\prime} \mathrm{N}$, long. $121^{\circ} 47^{\prime} \mathrm{E}$ ), were used for this study carried out between June and Dec. 2009. The average temperature, precipitation, and daylength data obtained from a nearby station of the Taiwan Central Weather Bureau are presented in Figure 1A. The natural daylength ranged between a minimum of $10 \mathrm{~h} 45 \mathrm{~min}$ at the winter solstice to a maximum of $13 \mathrm{~h} 32$ min at the summer solstice. The original genetic source of the clone was untraceable, but the clone was believed to be a hybrid $(H$. sp.) between $H$. undatus and $H$. polyrhizus judged from the characters of self-incompatible, red pulp, reddish margin of fruit scale, and stem ribs without a corneous margin. The pitaya plants were grown in rows with a single wire trellis system with $1.5-\mathrm{m}$ trellis height and $2.5 \mathrm{~m}$ between rows. Plastic supporting poles were installed at every $0.6 \mathrm{~m}$ in each row; and two plants planted nearby a pole were tied to the pole. Each experimental unit contained eight poles with 152 to 163 shoots, and all treatments were replicated with three units. A completely randomized design was used in all experiments. Shoots that flushed in the summer of 2009 were classified as new shoots, and shoots that flushed before the summer of 2009 were classified as old shoots. To ensure that only new shoots and new floral buds produced after the photoperiod manipulation treatments were taken into account, new shoots that emerged before 9 June 2009 were removed at the beginning of the study. In the study of off-season production in Pingtung, southern Taiwan (lat. $22^{\circ} 70^{\prime} \mathrm{N}$, long. $120^{\circ} 55^{\prime} \mathrm{E}$ ), 10 -year-old red pitaya plants in a commercial plantation were used. Each experimental unit was a row of $135 \mathrm{~m}$ in length containing 100 poles; and all treatments were replicated with five units. The temperature, daylength, and total daily photosynthetically active radiation $\left(P A R, \mathrm{~mol} \cdot \mathrm{m}^{-2} \cdot \mathrm{d}^{-1}\right)$ in Pingtung area obtained from a nearby station of the Taiwan Central Weather Bureau are presented in Figure 1B.

Treatments in summer. The treatments included daylength shortening (SD/S, short daylength in summer) and continuous floral bud thinning (FT/S, floral bud thinning in summer when the bud was $5 \mathrm{~cm}$ to $10 \mathrm{~cm}$ in length). The plants fruited naturally in summer 

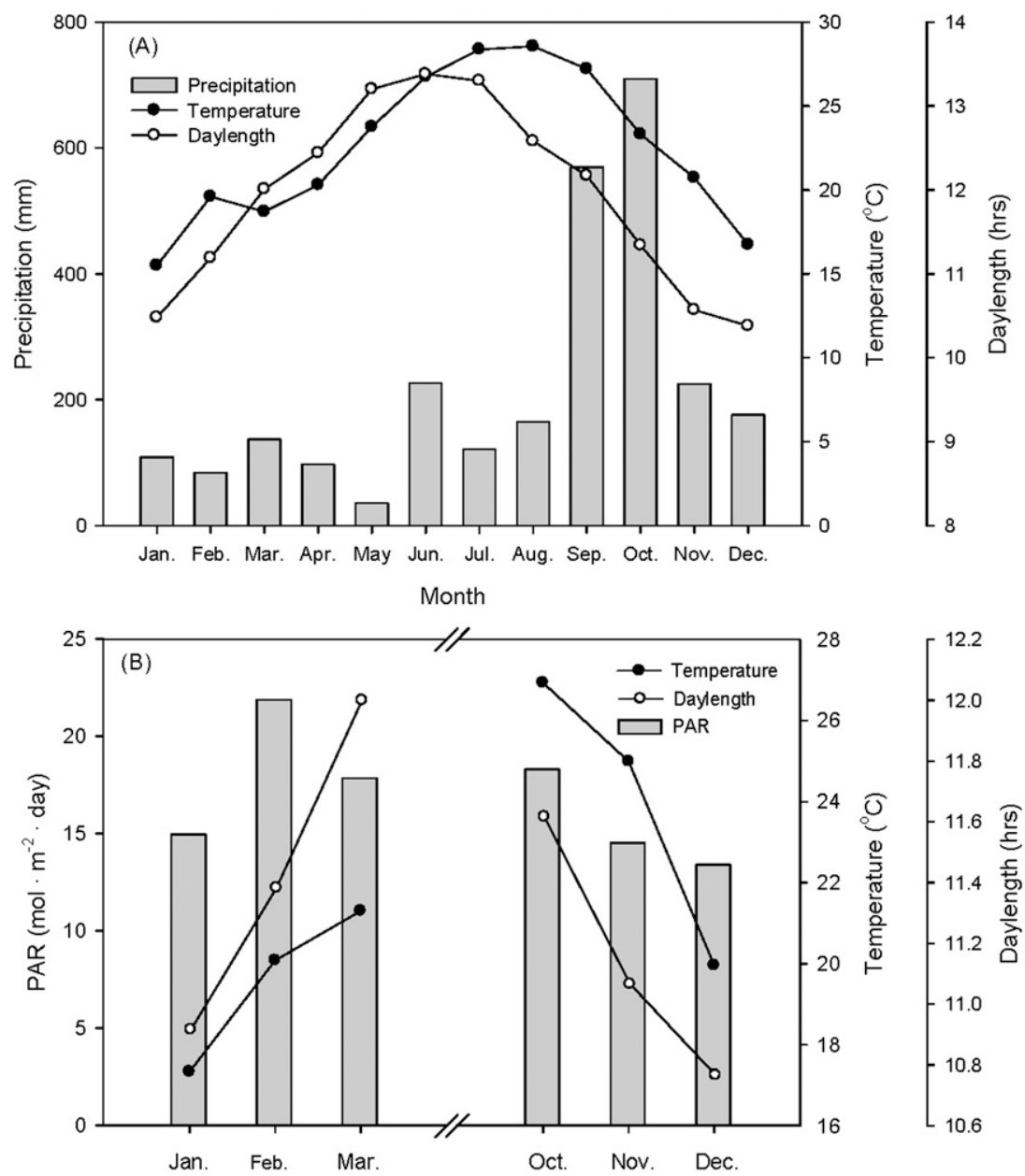

Fig. 1. (A) The monthly mean temperature and daylength and monthly accumulation of precipitation in 2009 at Yilan, Taiwan. (B) The monthly mean temperature, daylength, and photosynthetically active radiation $\left(P A R, \mathrm{~mol} \cdot \mathrm{m}^{-2} \cdot \mathrm{d}^{-1}\right)$ in the experimental period in 2011 at Pingtung, Taiwan.

were used as control $(\mathrm{CK} / \mathrm{S}$, control in summer). The SD/S-treated plants were exposed to sunlight from 1000 to $1800 \mathrm{HR}$ from 2 June to 2 Sept. 2009. A net cover installed $1 \mathrm{~m}$ above the plants, using four layers of $95 \%$ shadecloth (masking $95 \%$ of solar irradiation), was applied to shield the light (Fig. 2A) during the "dark" period. The photosynthetic photon flux density was $0 \mu \mathrm{mol} \cdot \mathrm{m}^{-2} \cdot \mathrm{s}^{-1}$ inside the net cover and $1581 \pm 24 \mu \mathrm{mol} \cdot \mathrm{m}^{-2} \cdot \mathrm{s}^{-1}$ outside (measured with a LI-250A light meter between 0940 and 0945 HR on 20 Aug. 2009). The vegetative growth and floral bud formation data of the experimental plants were recorded weekly throughout the experiment.

Winter night-breaking. The night-breaking treatment was conducted during the period of 17 Sept. to $21 \mathrm{Dec}$. 2009. The plants were provided $4 \mathrm{~h}$ ( 2200 to $0200 \mathrm{HR}$ ) of additional light daily using incandescent bulbs (TC115 V100W; China Electric Mfg. Co., Taiwan). The bulbs were placed $30 \mathrm{~cm}$ above the plants at $1.5-\mathrm{m}$ intervals in lines located between every two rows (Fig. 2B). The plants of $\mathrm{SD} / \mathrm{S}$, $\mathrm{FT} / \mathrm{S}$, and half of the $\mathrm{CK} / \mathrm{S}$ received the nightbreaking treatment $(\mathrm{SD} / \mathrm{S}+\mathrm{NB} / \mathrm{W}, \mathrm{FT} / \mathrm{S}+\mathrm{NB} /$ $\mathrm{W}$, and $\mathrm{CK} / \mathrm{S}+\mathrm{NB} / \mathrm{W})$, whereas the other half of $\mathrm{CK} / \mathrm{S}$ did not receive any treatments throughout. The vegetative growth and floral bud formation data were recorded weekly throughout the experiment.

Off-season fruit production. The off-season fruit inductions treatments were carried out between 27 Dec. 2010 and the March equinox of 2011 and between 14 Oct. 2011 and 10 Nov. 2011 in a commercial plantation in Pingtung. The night-breaking lasted $6 \mathrm{~h}$ (2100 to $0300 \mathrm{HR}$ ) each day using 28 -W warm white fluorescent lamps (EF3R28L-EX220; Grand Halo Technology Co. Ltd., Taiwan). The vegetative growth and floral bud formation data of 24 randomly selected new shoots per experimental unit were recorded weekly throughout the experiment.

Statistical analysis. SAS software (SAS Institute Inc., Cary, NC) was used to analyze the data. The resulting values were means \pm SE of at least three units. The least significant difference test was used to compare treatments when the analysis of variance showed significant differences between means.

\section{Results}

Shortening daylength in the summer inhibited flowering and promoted vegetative growth of red pitaya. For control plants, $47.4 \%$ of shoots flowered and $11.9 \%$ of shoots sprouted new shoots in the summer (Table 1). Shortening daylength in summer caused floral bud formation to cease (Figs. 2A and 2C) and promoted new shoot sprouting (Fig. 2C; Table 1). Continuous thinning of floral buds on old shoots enhanced more floral bud formation but not young shoot sprouting (Fig. 3A-B). For new shoots that flushed in the summer of 2009, no floral bud formation occurred regardless of daylength treatments, but floral bud formation was found in new shoots on plants subjected to continuous floral bud thinning (FT/S) (Fig. 3C). The cumulative percentage of summer sprouting increased fivefold by short-day treatment (Table 1). The sprouting occurred solely at the proximal ends of the old shoots, which were maintained under short-day conditions during the summer (SD/ S) (Fig. 2C). The ribs of all winter shoots and the ribs of summer shoots on $\mathrm{SD} / \mathrm{S}$-treated plants were straight, but the ribs of most summer shoots on control plants were spiral (Fig. 4A-B).

Night-breaking treatment contributed to winter flowering of red pitaya. The nightbreaking treatment was effective in promoting winter flowering of red pitaya (Figs. 2B and 2D). For old shoots, the percentage of winter flowering was highest in shoots that were grown under short daylength during summer $(\mathrm{SD} / \mathrm{S})$ and received night-breaking treatment in the winter $(\mathrm{NB} / \mathrm{W})$ (Fig. 5A). After flowering on 1 Oct. 2009 (Fig. 5A), control plants did not flower again throughout the rest of experiment period (Fig. 2F). The night-breaking treatment was effective on promoting floral bud formation in winter in the old as well as new shoots (Figs. 5A and 5C), but the treatment was more effective on promoting young shoots in new shoots than in old shoots (Figs. 5B and 5D). The percentages of shoots that flowered after the night-breaking treatment ranged from $18.2 \%$ to $27.7 \%$ among shoots that received different summer treatments, but none of the control shoots without night-breaking flowered (Table 1).

Off-season fruit production. Two sets of night-breaking treatments were conducted to test the treatment effect on winter and spring fruit production. The night-breaking treatment applied between 27 Dec. 2010 and the March equinox of 2011 resulted in $88 \%$ of the shoots to flower and it reduced shoots sprouting by $40 \%$ (Table 2 ). The majority of the floral buds appeared in late Mar. 2011 in this treatment (Table 2). The night-breaking treatment applied between 14 Oct. and 10 Nov. 2011 also resulted in $88 \%$ of the shoots to flower (Table 2 ), and the floral buds appeared by 10 Nov. 2011.

\section{Discussion}

Flowering of long-day plants can be induced by the increased daylength after the March equinox (Borchert et al., 2005; Garner and Allard, 1920). In pitaya, the meristems located beneath the areoles, which are gray structures with hairs and spines developed on the ribs of a shoot, can differentiate into floral buds in response to increased daylength. In 


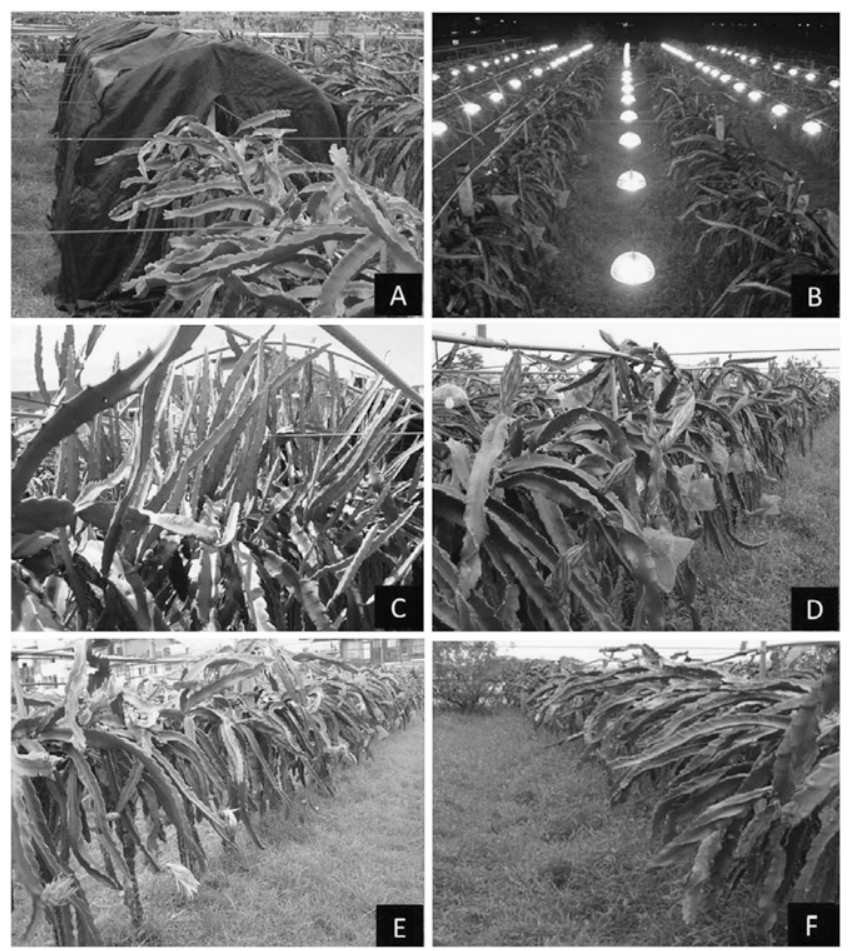

Fig. 2. Sprouting of the plants under daylength shortening treatment from 2 June to 2 Sept. 2009 and flowering of the plants under night-breaking treatment from 17 Sept. to 21 Dec. 2009. (A) The facility for daylength shortening; (B) the facility for night-breaking; (C) the sprouting of the plants under daylength shortening treatment in summer; (D) the flowering and sprouting of the plants under nightbreaking treatment in winter; (E) the flowering and sprouting of control plants in summer; and (F) the sprouting of control plants in winter.

Table 1. The effect of daylength shortening, continuous floral bud thinning and night-breaking treatments on the sprouting and flowering of $H$. sp.

\begin{tabular}{|c|c|c|c|c|}
\hline & \multicolumn{4}{|c|}{$\begin{array}{c}\text { Summer season treatments- shorting daylength }(\mathrm{SD} / \mathrm{S}) \text {, } \\
\text { continuous flower thinning }(\mathrm{FT} / \mathrm{S})\end{array}$} \\
\hline & \multicolumn{2}{|c|}{$\begin{array}{l}\text { Accumulative percentage } \\
\text { (19 June to } 3 \text { Sept. 2009) }\end{array}$} & \multicolumn{2}{|c|}{$\begin{array}{l}\text { Avg number }{ }^{y} \text { (19 June to } \\
3 \text { Sept. 2009) }\end{array}$} \\
\hline & Sprouting shoot (\%) & Flower-budded shoot (\%) & Sprout & Floral bud \\
\hline$\overline{\mathrm{SD} / \mathrm{S}^{\mathrm{x}}}(8 \mathrm{~L} / 16 \mathrm{D})$ & $62.6 \pm 3.9 \mathrm{a}$ & $0.0 \pm 0.0 \mathrm{c}$ & $2.5 \pm 0.3 \mathrm{a}$ & $0.0 \pm 0.0 \mathrm{c}$ \\
\hline $\mathrm{FT} / \mathrm{S}$ & $17.0 \pm 4.1 \mathrm{~b}$ & $91.7 \pm 1.8 \mathrm{a}$ & $1.8 \pm 0.2 \mathrm{a}$ & $5.4 \pm 0.1 \mathrm{a}$ \\
\hline $\mathrm{CK} / \mathrm{S}$ & $11.9 \pm 1.6 \mathrm{~b}$ & $47.4 \pm 2.8 \mathrm{~b}$ & $2.0 \pm 0.2 \mathrm{a}$ & $1.6 \pm 0.0 \mathrm{~b}$ \\
\hline
\end{tabular}

Winter season treatments-night-breaking $4 \mathrm{~h}(\mathrm{NB} / \mathrm{W})$

\begin{tabular}{lcccc} 
& \multicolumn{3}{c}{ Winter season treatments-night-breaking 4 h (NB/W) } \\
\cline { 2 - 5 } & \multicolumn{2}{c}{$\begin{array}{c}\text { Accumulative percentage } \\
\text { (13 Oct. to 21 Dec. 2009) }\end{array}$} & $\begin{array}{c}\text { Avg number (13 Oct. to 21 } \\
\text { Dec. 2009) }\end{array}$ \\
\hline $\mathrm{SD} / \mathrm{S}+\mathrm{NB} / \mathrm{W}^{\mathrm{w}}$ & $2.6 \pm 1.0 \mathrm{~b}$ & $27.7 \pm 3.9 \mathrm{a}$ & $1.2 \pm 0.2 \mathrm{ab}$ & $1.9 \pm 0.1 \mathrm{a}$ \\
$\mathrm{FT} / \mathrm{S}+\mathrm{NB} / \mathrm{W}$ & $0.5 \pm 0.3 \mathrm{~b}$ & $20.8 \pm 3.1 \mathrm{ab}$ & $0.5 \pm 0.3 \mathrm{~b}$ & $1.4 \pm 0.1 \mathrm{~b}$ \\
$\mathrm{CK} / \mathrm{S}+\mathrm{NB} / \mathrm{W}$ & $2.4 \pm 0.7 \mathrm{~b}$ & $18.2 \pm 2.1 \mathrm{~b}$ & $1.6 \pm 0.5 \mathrm{a}$ & $1.7 \pm 0.2 \mathrm{ab}$ \\
$\mathrm{CK} / \mathrm{S}$ without NB & $8.6 \pm 2.5 \mathrm{a}$ & $0.0 \pm 0.0 \mathrm{c}$ & $1.3 \pm 0.1 \mathrm{ab}$ & $0.0 \pm 0.0 \mathrm{c}$ \\
\hline
\end{tabular}

${ }^{z}$ Total sprouting (flower-budded) shoot number/total shoot number.

y Total sprout (floral bud) number/total sprouting (flower-budded) shoot

x - /S mean treatment in summer season, for example: $\mathrm{SD} / \mathrm{S}$ mean shorting daylength in summer season. FT means continuous floral bud thinning and CK means control.

w_ $/ \mathrm{S}+\mathrm{NB} / \mathrm{W}$ mean treatment in summer season and night-breaking in winter.

Means within a column followed by the same letter(s) are not significantly different according to LSD test at the $5 \%$ level.

this study, floral buds of the first flush emerged from the old shoots on 14 May 2009, which was 8 weeks after the March equinox. Khaimov and Mizrahi (2006) demonstrated areole transformation in $H$. undatus by spraying CPPU, a cytokinin. In Israel, the areoles responded to natural daylength increase after mid-March and produced floral buds $\approx 14$ weeks later (in July). Areoles on plants sprayed with CPPU 4 weeks after the March equinox produced vegetative shoots by mid-May, and those sprayed 8 weeks after the March equinox produced floral buds by early June. It seemed that the areoles were actively differentiating and had determined to be a floral bud at the spray time 8 weeks after March equinox although dramatic morphological changes had not been obvious.
Taiwan is located $10^{\circ}$ south of Israel; the temperature during the flower induction period in Taiwan is higher than in Israel. Therefore, the meristems beneath areoles complete the process from induction to the appearance of floral buds within 8 weeks after the March equinox in Taiwan, 6 weeks earlier than in Israel. The areoles at the distal end of old shoots flowered first in mid-May (Fig. 3A), whereas numerous other areoles remained rested waiting for their priority to develop into flowers (Fig. 2E). Borchert et al. (2005) observed rapid flower emergence after the first flowering or after the removal of apical dominance, i.e., floral bud removal or fruit harvest. At early developmental stages, the floral buds are enclosed by spirally arranged bracteoles (Almeida et al., 2010), implying that the spiral orientation was a sign of successful flower induction. Therefore, the spiral shape of ribs of summer-sprouted shoots might be related to partial evocation of the areoles (Fig. 4).

Shortening daylength in summer as well as night-breaking with artificial lighting in winter reversed the flowering phenology in red pitaya (Fig. 2). The resting buds waiting for flower development ceased to develop after receiving daylength shortening treatment, implying that a long day is required for further flower differentiation (Fig. 3A). Daylength extension or night-breaking may regulate the vegetative and reproductive growth of cactus plants (Boyle, 1991; Gutterman, 1995). Yen and Chang (1997) reported the effect of prolonging the light period to 2200 HR in winter on inducing $H$. undatus plants to flower, but the quantity of winter flowers so produced was not stable enough for commercial production. Khaimov and Mizrahi (2006) were unable to alter flowering by extending the daylength between March and July in Israel. Because the daylength during the experimental period already exceeded the critical length required for floral induction of pitaya, further extension would not affect flowering (Khaimov and Mizrahi, 2006). In Taiwan, the daylength during the period from the September equinox to the winter solstice varies between $12 \mathrm{~h} 7 \mathrm{~min}$ and $10 \mathrm{~h} 45 \mathrm{~min}$ and is not long enough to fulfill the requirement to complete the floral differentiation. Therefore, the last flowering of the old shoots on control plants occurred on 1 Oct. 2009 (Fig. 5A). After receiving the night-breaking treatment, flowering resumed after that point (Fig. 5A), however. It seemed that the critical daylength for red pitaya flower initiation and differentiation was close to the daylength at equinox.

In the summer, continuous thinning of floral buds, which had a similar effect of continuous removal of apical dominance, resulted in more shoots to produce flower buds and higher average number of floral buds per shoots (Table 1). The night-breaking treatment applied from 17 Sept. to 21 Dec. 2009 induced winter flowering regardless of shoot treatment during the summer. For the control shoots $(\mathrm{CK} / \mathrm{S})$, which received no treatment in the summer, $18 \%$ of the shoots flowered 

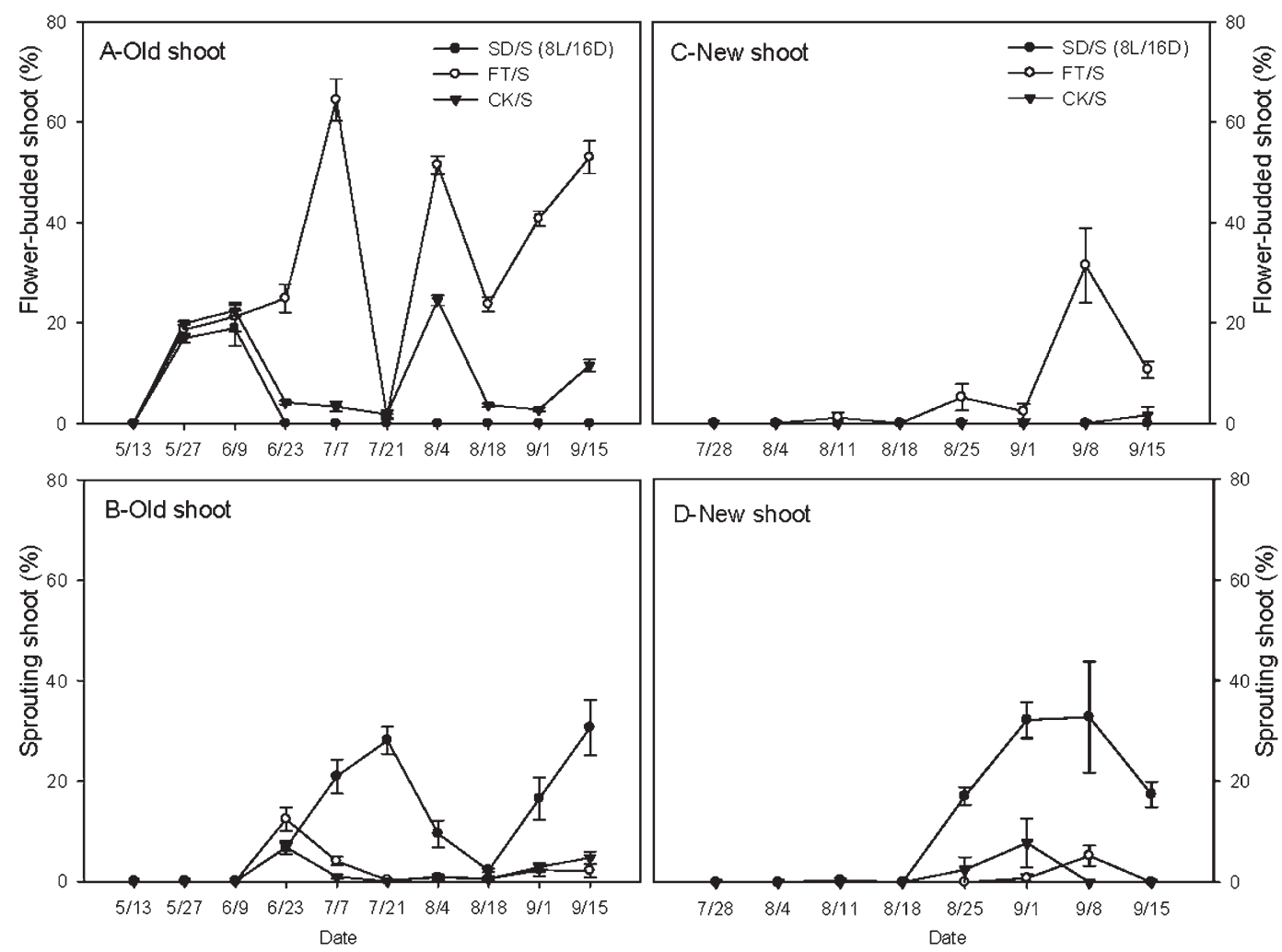

Fig. 3. The effect of daylength shortening (SD/S) and continuous floral bud thinning (FT/S) treatments in summer on floral bud formation and sprouting: (A) the percentage of shoots with floral bud(s) among the old shoots; (B) the percentage of sprouting shoots among the old shoots; (C) the percentage of shoots with floral bud(s) among the new shoots; and (D) the percentage of sprouting shoots among the new shoots. The daylength shortening treatment was applied from 2 June to 2 Sept. 2009. The control plants (CK/S) did not receive any treatment.

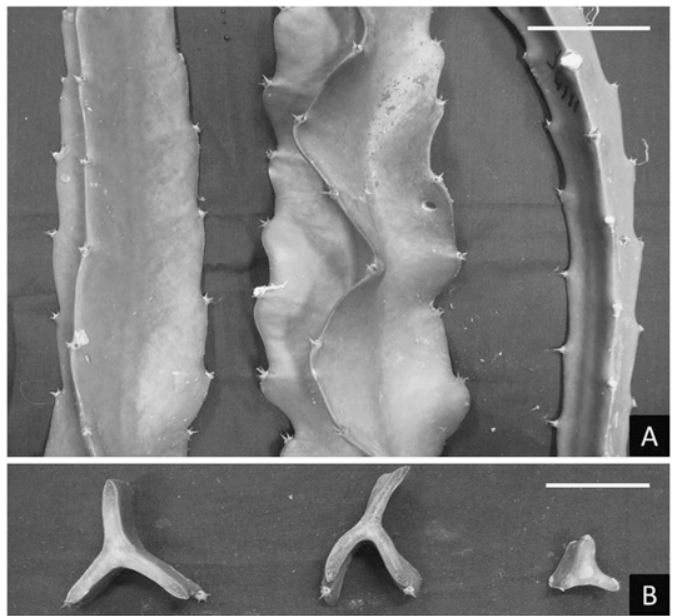

Fig. 4. The morphology of shoots: (A) side view; and (B) cross-sectional view. The three specimens from left to right include a shoot that sprouted during the previous winter, a new shoot sprouted in the summer $(\mathrm{CK} / \mathrm{S})$, and a new shoot sprouted in the summer under daylength shortening treatment $(\mathrm{SD} / \mathrm{S})$. $\mathrm{Bar}=5 \mathrm{~cm}$.

during the 3 months of night-breaking application in northeastern Taiwan.

In the trial of off-season fruit production in 2011 in southern Taiwan, massive flowering appeared near the end of 3-month nightbreaking treatment applied from January to March and of 1-month treatment applied from mid-October to mid-November (Table 2 ). The average total daily $P A R$ was between 15 and $21 \mathrm{~mol} \cdot \mathrm{m}^{-2} \cdot \mathrm{d}^{-1}$ (Fig. 1B) and the average day and night temperatures were 27 and $22^{\circ} \mathrm{C}$ between 14 Oct. and 10 Nov. 2011, presumably adequate for $H$. undatus to have maximal daily net $\mathrm{CO}_{2}$ uptake (Nobel and De La Barrera, 2004). In the period between Jan. and Mar. 2011, the average total daily $P A R$ was not lower than that of the period between October and November (Fig. 1B), but the ture might be a factor that accounted for the temperature was lower. Thus, the tempera- difference in the time required for promoting flowering. In the winter and early spring (January to March) of 2011, half of the time in days the night temperatures were between 10 and $15^{\circ} \mathrm{C}$ the temperature that might lead to $50 \%$ drop from the maximal daily net $\mathrm{CO}_{2}$ uptake in $H$. undatus (Nobel and De La Barrera, 2004). Seasonal flowering of $H$. polyrhizus and $H$. spp. shares similar phenology with $H$. undatus (Nerd et al., 2002). Therefore, we postulated that the temperature in late fall in southern Taiwan was adequate for $H$. sp. flower differentiation; thus, the required night-breaking time was short. The duration of night-breaking treatment for successful offseason fruit production should be longer as the temperature drops in winter. The off-season fruit production data (Table 2) also suggested that night-breaking treatment might be commercially applicable for the entire short-day period from October to March for off-season red pitaya production, at least in southern Taiwan.

Red pitaya is hereby confirmed to be a long-day plant whose flowering and major sprouting processes switched at the equinoxes in subtropical Taiwan. Areoles on the old shoots may be induced to flower naturally after the March equinox. Hylocereus spp. forms floral buds in two to three waves between May and October in Taiwan (Hsu, 2004) as well as in Israel (Khaimov and Mizrahi, 2006). Red pitaya shoots that sprout after June may have enough time for their areoles to complete the induction process 

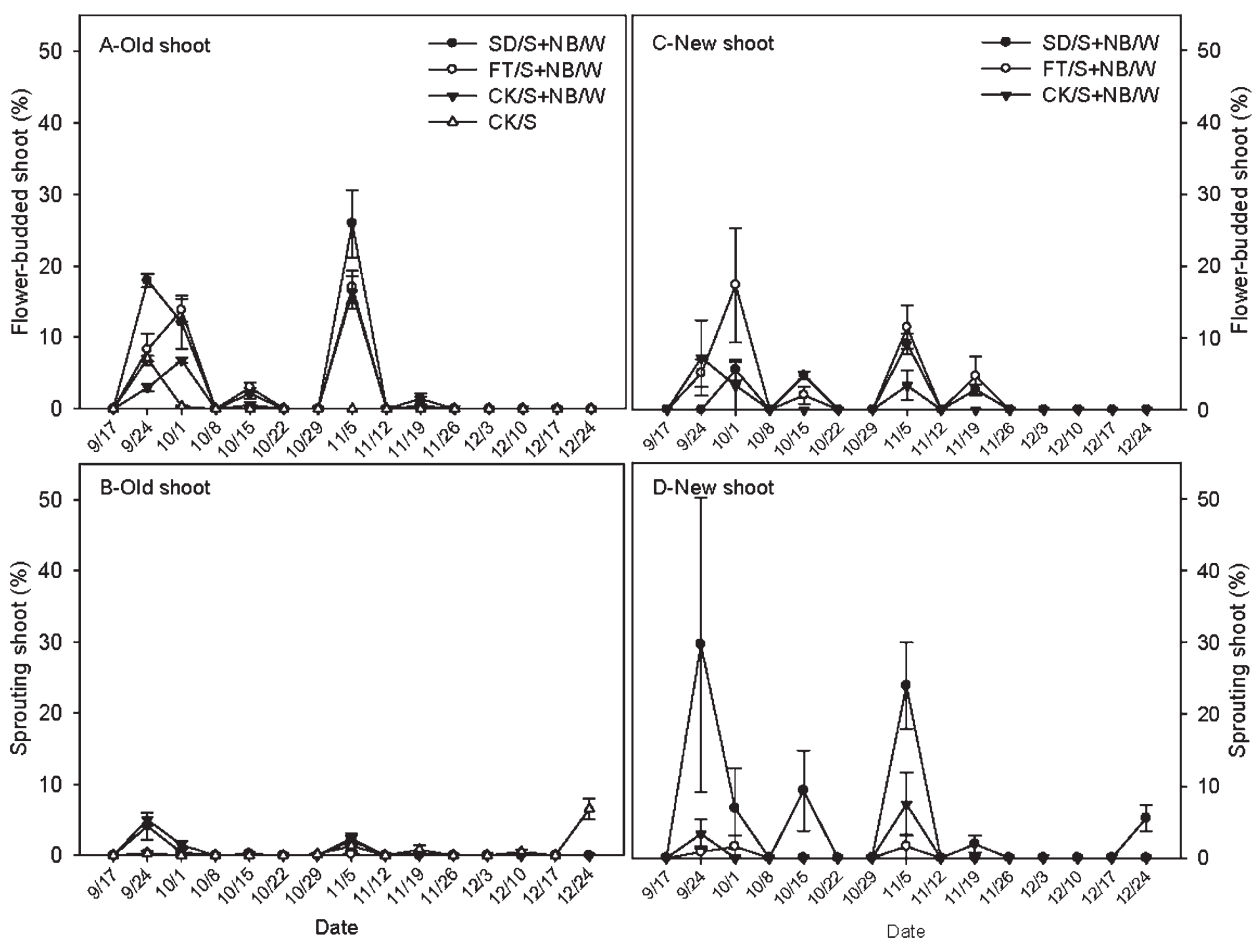

Fig. 5. The effect of night-breaking treatment for $4 \mathrm{~h}$ in winter on floral bud formation and sprouting: (A) the percentage of flower-budded shoots among old shoots; (B) the percentage of sprouting shoots among the old shoots; (C) the percentage of flower-budded shoots among the new shoots; and (D) the percentage of sprouting shoots among the new shoots. All plants from the summer experiment were used for the night-breaking experiment (NB/W, night-breaking in the winter); thus, the treatments were designated as $\mathrm{SD} / \mathrm{S}+\mathrm{NB} / \mathrm{W}$ and $\mathrm{FT} / \mathrm{S}+\mathrm{NB} / \mathrm{W}$. Half of the summer control plants received the night-breaking treatment (CK/ $\mathrm{S}+\mathrm{NB} / \mathrm{W})$, and the other half did not receive any treatment throughout the experiment (CK/S). The night-breaking treatment was applied from 17 Sept. to 21 Dec. 2009.

Table 2. The effect of night-breaking treatment on the sprouting and flowering of $H$. sp. in the noninductive period of 2011 .

\begin{tabular}{lcccr}
\hline & \multicolumn{2}{c}{ Accumulative percentage } & \multicolumn{2}{c}{ Avg number $^{\mathrm{y}}$} \\
\cline { 2 - 5 } & Sprouting shoot (\%) & Flower-budded shoot (\%) & Sprout & Floral bud \\
\hline & & 27 Dec. 2010 to 20 Mar. 2011 & & \\
NB & $58.3 \pm 9.8 \mathrm{~b}$ & $88.3 \pm 8.1 \mathrm{a}$ & $3.2 \pm 0.4 \mathrm{a}$ & $2.6 \pm 0.3 \mathrm{a}$ \\
CK & $98.3 \pm 1.6 \mathrm{a}$ & $0.0 \pm 0.0 \mathrm{~b}$ & $3.1 \pm 0.4 \mathrm{a}$ & $0.0 \pm 0.0 \mathrm{~b}$ \\
& & & \\
NB & $6.7 \pm 4.9 \mathrm{a}$ & 14 Oct. 2011 to 10 Nov. 2011 & & \\
CK & $21.7 \pm 6.8 \mathrm{a}$ & $88.3 \pm 5.0 \mathrm{a}$ & $0.4 \pm 0.2 \mathrm{~b}$ & $3.4 \pm 0.2 \mathrm{a}$ \\
\hline
\end{tabular}

${ }^{2}$ Total sprouting (flower-budded) shoot number/total shoot number.

' Total sprout (floral bud) number/total sprouting (flower-budded) shoot.

Means within a column followed by the same letter(s) are not significantly different according to LSD test at the $5 \%$ level.

but not to differentiate into floral buds before the September equinox. The daylength after the September equinox is not long enough for the undifferentiated areoles to complete the differentiation into floral buds. Night-breaking treatment between the September and the March equinoxes helps the areoles to complete flower differentiation and has economic potential for winter production of pitaya fruit.

\section{Literature Cited}

Almeida, O.J.G., A.A. Sartori-Paoli, and L.A. Souza. 2010. Flower morpho-anatomy in Epiphyllum phyllanthus (Cactaceae). Rev. Mex. Biodiv. 81:65-80.

Borchert, R., S. Renner, Z. Calle, D. Navarrete, A. Tye, L. Gautier, R. Spichiger, and P. von Hildebrand. 2005. Photoperiodic induction of synchronous flowering near the Equator. Nature 433:627-629.

Boyle, T. 1991. Temperature and photoperiodic regulation of flowering in 'Crimson Giant' Easter cactus. J. Amer. Soc. Hort. Sci. 116:618-622.

Chang, T. 2003. Yield and quality of pitaya (Hylocereus undatus Britt. \& Rose) as affected by fruiting regulation. MS thesis, Natl. Chung Hsing Univ., Taiwan.

Garner, W.W. and H.A. Allard. 1920. Effect of the relative length of day and night and other factors of the environment on growth and reproduction in plants. J. Agr. Res. 18:553-606.

Gutterman, Y. 1995. Environmental factors affecting flowering and fruit development of Opuntia ficus-indica cuttings during the 3 weeks before planting. Isr. J. Plant Sci. 43:151-157.

Hsu, W. 2004. Investigations on culture, growth habits and phenology in pitaya (Hylocereus spp.). MS thesis, Natl. Taiwan Univ., Taiwan.

Jiang, Y., T. Lin, C. Lee, C. Yen, and W. Yang. 2011. Phenology, canopy composition, and fruit quality of yellow pitaya in tropical Taiwan. HortScience 46:1497-1502.

Jiang, Y.L. 2005. Classification, flowering and fruiting characteristics, and pruning of climbing cactus. MS thesis, Natl. Taiwan Univ., Taiwan.

Khaimov, A. and Y. Mizrahi. 2006. Effects of daylength, radiation, flower thinning and growth regulators on flowering of the vine cacti Hylocereus undatus and Selenicereus megalanthus. J. Hort. Sci. Biotechnol. 81:465-470.

Luders, L. and G. McMahon. 2006. The pitaya or dragon (Hylocereus undatus). Agnote 778, No. D42. Northern Territory Government.

Mizrahi, Y. and A. Nerd. 1999. Climbing and columnar cacti: New arid land fruit crops. Perspectives on new crops and new uses, p. 358-366. In: Janick, J. (ed.). ASHS Press, Alexandria, VA.

Mizrahi, Y., A. Nerd, and P.S. Nobel. 1997. Cacti as crops. Hort. Rev. 18:291-391.

Mizrahi, Y., A. Nerd, and Y. Sitrit. 2002. New fruit for arid climates, p. 378-384. In: Janick, J. (ed.). Trends in new crops and new uses. ASHS, Alexandria, VA.

Nerd, A., Y. Sitrit, R.A. Kaushik, and Y. Mizrahi. 2002. High summer temperatures inhibit flowering in vine pitaya crops (Hylocereus spp.). Sci. Hort. 96:343-350.

Nobel, P.S. and E. De La Barrera. 2004. $\mathrm{CO}_{2}$ uptake by the cultivated hemiepiphytic cactus, Hylocereus undatus. Ann. Appl. Biol. 144:1-8.

Raveh, E., A. Nerd, and Y. Mizrahi. 1998. Responses of two hemiepiphytic fruit crop cacti to different degrees of shade. Sci. Hort. 73:151-164.

Yen, C. and F. Chang. 1997. Forcing pitaya (Hylocereus undatus Britt. \& Rose) by chemicals, controlled daylength and temperature. Proc. Symp. Enhancing Competitiveness of Fruit Ind., Taichung District Agricultural Improvement Station. Taiwan. 3:163-170. 